\title{
Post-Activation Potentiation Effect after Acute Plyometric Exercises on the Performance of Long Jumpers
}

\author{
D. dos Santos Silva1,2, A. R. P. Ferreira5, F. J. Aidar ${ }^{1-3}$, D. Gama de Matos ${ }^{3}$, \\ E. Kalinine1, M. E. Da Silva-Grigoletto ${ }^{1,2}$, R. F. de Souza ${ }^{1-4}$ \\ 1 Department of Physical Education, Federal University of Sergipe - UFS, São Cristóvão, Sergipe, Brazil \\ 2 Graduate Program in Master's level in Physical Education, Federal University of Sergipe - UFS, São Cristóvão, \\ Sergipe, Brazil \\ ${ }^{3}$ Group of Studies and Research of Performance, Sport, Health and Paralympic Sports - GEPEPS, Federal \\ University of Sergipe - UFS, São Cristóvão, Sergipe, Brazil \\ ${ }^{4}$ Racing Club, Federal University of Sergipe - UFS, São Cristóvão, Sergipe, Brazil \\ ${ }^{5}$ College of Physical Education and Exercise Science, University of Brasília, Brasilia, Brazil
}

\section{CORRESPONDING AUTHOR:}

Devisson dos Santos Silva

Departamento de Educação Física

Centro de Ciências Biológicas

Universidade Federal de Sergipe

Avenida Marechal Rondon

S/N - Jardim Rosa Elze - São Cristóvão/

SE - 49100-000

Cidade Universitária "Prof. José Aloísio de

Campos"

São Cristóvão

Sergipe, Brazil

E-mail: devissonedfisica@gmail.com

\section{DOI:}

10.32098/mltj.03.2021.14

LEVEL OF EVIDENCE: 2B

\begin{abstract}
SUMMARY
Background. Post-activation potentiation (PAP) is a technique that aims to optimize yield by performing stimuli minutes before the main activity. However, the effect of plyometric exercise (PE) for long jumpers PAP and the effective recovery interval is not understood. This study aimed to evaluate the effect of PE at different rest intervals as a strategy for long jumpers PAP.

Methods. The sample consisted of 11 young athletes $(16.2 \pm 1.3$ years; $57.8 \pm 7.9 \mathrm{~kg}$ and $166 \pm 12 \mathrm{~cm}$ ), who performed horizontal jump under different resting times after PAP: 1) PE + 1 minute break (P1min); PE + 3 minutes apart (P3min); control condition (C) performed only the jump. The following variables were evaluated: Squat Jump (SJ), Counter Movement Jump (CMJ), Approach velocity in the last 15 meters (Vel_15m), Contact Time at the Push Board (CT), Height and Distance of the jump.

Results. The contact time on the impulse board was shorter in the P1min condition $(14.63 \pm 0.94 \mathrm{~s}$ vs $15.27 \pm 0.81 \mathrm{~s} ; \mathrm{p}=0.05$; Cohen's $\mathrm{d}=0.72)$ and P3min vs control ( $14.36 \pm 0.89 \mathrm{~s} v \mathrm{~s} 15.27 \pm 0.81 \mathrm{~s} ; \mathrm{p}=0.009$; Cohen's $\mathrm{d}=1.06$ ); the height of the jump was higher at $\mathrm{P} 1 \mathrm{~min}(180.16 \pm 7.08 \mathrm{~cm}$ vs $173.44 \pm 12.70 \mathrm{~cm} ; \mathrm{p}=0.043$; Cohen's $\mathrm{d}=0.06)$ and $\mathrm{P} 3 \mathrm{~min}$ vs control $(182.30 \pm 10.68 \mathrm{~cm}$ vs $173.44 \pm 12.70 \mathrm{~cm} ; \mathrm{p}=0.005$; Cohen's $\mathrm{d}=$ $0.07)$. The variables approach velocity, CMJ, SJ and jump distance did not differ.

Conclusions. From the current results, PE can be an effective strategy to reduce the contact time on the jump board and increase height of the jump in young competing in long jump.
\end{abstract}

\section{KEY WORDS}

Post activation potentiation; plyometric exercise; long jump; rest interval; contact time; height of the jump.

\section{BACKGROUND}

Long jump performance depends on training in power, speed, agility, and specific techniques such as post-activation training (PAP), commonly applied during immediate preparation for athletic performance (1). It is believed that PAP can optimize the performance of jumpers by pre-main activity stimuli that produce a temporary increase in muscle contraction capacity, provided that the contractile activity is not fatigue inducing (2). Evidence indicates that short and intense contractions dramatically potentiate the muscle's ability to produce strength (3) and recruit motor units (4). Other such mechanisms include neuronal facilitation, change in mechanical and intrinsic 
muscle properties, modification of the sarcomere flexion angle, and increase in sensitivity to calcium influx (5). Several studies have demonstrated PAP-induced improvement in counter movement jump (CMJ) performance (6) and sprint (7).

Although isometric and dynamic voluntary contractions are the main mechanisms that promote $\mathrm{PAP}(8)$, there is no conclusive evidence specifically on the underlying mechanisms stimulated by plyometric exercise (PE) in long jump athletes $(1,7)$. PEs are traditionally used in training that has essentially characteristics for muscle power $(9,10)$, and there is a strong relationship in the optimization of jumping performance during training (1), the stimulated PE could be an alternative PAP technique, complementary and strategic to traditional warmup methods applied during a competitive routine.

Inadequate volumes and intensities of $\mathrm{PE}$ without providing an appropriate muscle recovery time during a warm-up routine, on the contrary, may cause muscle wear and, consequently, performance reduction (7). Moreover, the range between short (0.3-4 $\mathrm{min}$ ) (11) and long (5-9 $\mathrm{min})$ (12) recuperative intervals is large and undefined. Thus, there is a need to further clarify the dose-dependent relationship (5) of the ideal time interval between PAP and the main activity. On the basis of these findings, we hypothesize that the PAP through PE execution preceding the long jump with a specific recovery period can improve performance in young athletes. In this study, we sought to evaluate the effect of PE as a PAP strategy under three different interval conditions on the performance of long jumpers.

\section{METHODS}

\section{Experimental approach to the problem}

The study was performed at the end of the competitive season on the athletic track of the Federal University of Sergipe, covered with synthetic flooring, validated by the International Association of Athletics Federations. All athletes performed three simulated long jump competitions, with variations in the rest interval after PAP. Evaluations were carried out at 7-day intervals. Throughout the study period, the athletes remained active, but without participating in any other sporting event, requiring a 24 -h rest before the evaluations.

All the participants performed a standardized warm-up protocol consisting of dynamic stretching, followed by two 15 -m accelerations, three flight steps, and two full jumps in the sandbox (figure 1).

\section{Subjects}

The study sample comprised 11 volunteer young athletes (age, $16.2 \pm 1.3$ years; body weight, $57.8 \pm 7.9 \mathrm{~kg}$; and $166 \pm$
$12 \mathrm{~cm})$. The athletes were long jump competitors participating in the under- 18 category state championship, in the state of Sergipe, Brazil, from 2014 to 2016.

The inclusion criteria were as follows: one-year competitive experience in long jump competitions and specific performance between the distances of 4.50 and $7.00 \mathrm{~m}$ of horizontal jump in the sandbox. Athletes who reported musculoskeletal injuries and use of any nutritional supplement in the 6 months prior to the study were excluded. All athletes signed an informed consent form, which specified the details relevant to the study and the risks involved in the study procedures. This study was approved by the Research Ethics Committee of the Health Sciences Sector of the Federal University of Sergipe, UFS (CAAE-08879219.6.0000.5546). The study procedures complied with the standards of ethics in human research, in accordance with the National Health Council Resolution No. 466/12, a regulatory standard for research involving human beings, and the Declaration of Helsinki World Medical Association (1964, reformulated in 1975, 1983, 1989, 1996, 2000 and 2008). The research was conducted ethically according to international standards and as required by the Muscle, Ligaments and Tendons Journal (13).

\section{Plyometric exercise}

$\mathrm{PE}$ was performed through four continuous single-leg vertical jump for each leg. During the evaluation, the participants performed five long jump, with an interval of $10 \mathrm{~min}$

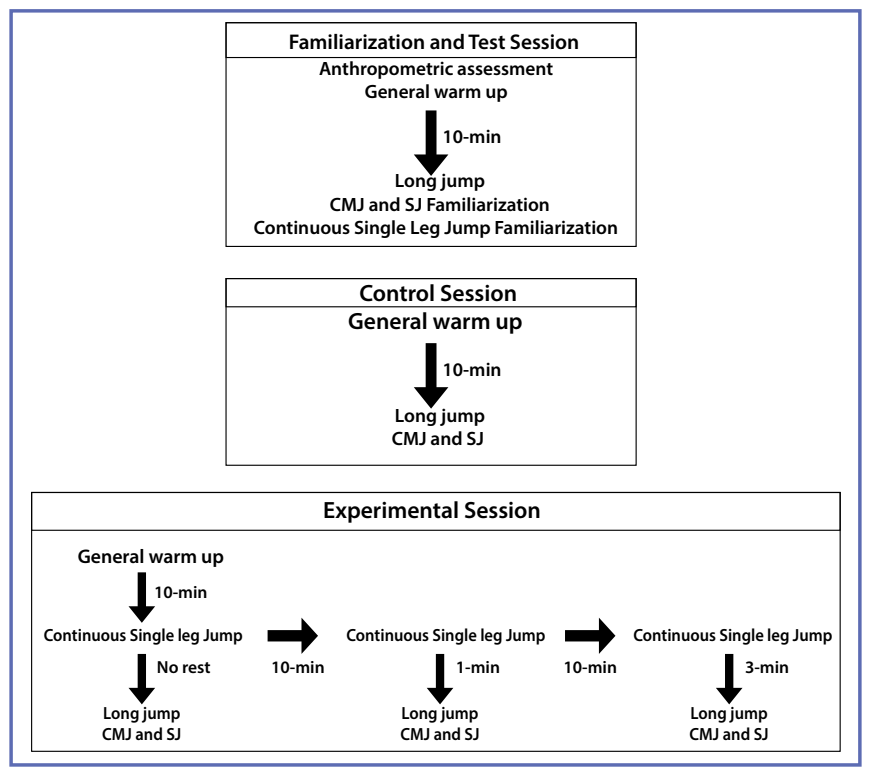

Figure 1. Experimental protocol: effect of post-activation potentiation on long jumpers.

CMJ: counter movement jump; SJ: squat jump; min: minutes. 
between each jump. During the intervals, PAP was measured at different rest times: 1-min rest after PE (P1min); 3-min rest after PE (P3min); and no rest after PE (Control, C). During the rest, the athletes performed passive recovery.

\section{Squat jump and counter movement jump}

The SJ and CMJ were evaluated $30 \mathrm{~s}$ before the long jump. For conducting the tests, a $50 \times 60 \mathrm{~cm}$ conductive surface contact pad (Probotics Inc., USA) connected to a display (Probotics Inc., USA) was used. The height of the vertical jump was defined as the time interval between the loss of contact of the feet with the mat and subsequent contact after the fall (14).

\section{Approach velocity and time of contact with the thrust board}

The approach velocity of the athletes in the last $15 \mathrm{~m}$ was assessed using two pairs of photocells (Probotics Inc., USA) positioned at 16 and $1 \mathrm{~m}$ from the push board. The time of contact with the impulse board was calculated after filming (Casio Computer Co., Ltd., Tokyo, Japan), being defined as the number of frames of the temporal interval between the beginning and the loss of total contact of the feet with the ground.

\section{Height and long jump performance}

The jump height was assessed using a high-speed $(300 \mathrm{~Hz})$ digital video camera (CasioExilim Pro EX F1, Tokyo, Japan) set at a distance of $1.60 \mathrm{~m}$ from the sandbox. The optical axis of the chamber was perpendicular to the front edge line of the jump drive board. The field of view was widened at 8 $\mathrm{m}$ (4- $\mathrm{m}$ before and 4-m after the push board). Video analysis was performed using the adobe after-effects cc 2017 programs and the pictures were taken using the Kinovea 0.8.15 program (15). To determine this analysis, luminescent markers for anatomical reference were fixed on the iliac crest. To quantify the horizontal distance of the long jump, a 50-m measuring tape (Vonder, Paraná, Brazil) was used. According to the official competition rules regarding long jump, horizontal distance of the long jump was defined as the distance between the mark made on the sand by the athlete's fall and the edge of the take-off board.

\section{Statistical analysis}

Data are presented as mean \pm standard deviation (S.D.). The Shapiro-Wilk test was used to verify the normality of the variables, considering the sample size. Possible differences between the groups were evaluated using the ANOVA (one-way) test, Bonferroni post hoc test for parametric data, and Kruskal-Wallis for nonparametric data, Dunn's post hoc tests were used to determine the differences between pairs. The effect size was measured using the Cohen's d test. Pearson's test was used to determine the correlations. Statistical analysis was performed using the Statistical Package for the Social Science, version 20.0, software. A p value of $<0.05$ was considered significant.

\section{RESULTS}

Compared with the control group, the contact time on the impulse board was shorter in the P1min group (15.27 \pm 0.81 $\mathrm{s}$ vs $14.63 \pm 0.94 \mathrm{~s} ; \mathrm{p}=0.05$; Cohen's $\mathrm{d}=0.72)$ and the $\mathrm{P} 3 \mathrm{~min}$ group $(15.27 \pm 0.81$ vs $14.36 \pm 0.89 \mathrm{~s} ; \mathrm{p}=0.009$; Cohen's $\mathrm{d}=$ 1.06) (figure $\mathbf{2} \mathbf{b}$ ). Compared with the control group, the heel height was higher in the P1min group $(173.44 \pm 12.70 \mathrm{~cm} v \mathrm{~s}$ $180.16 \pm 7.08 \mathrm{~cm} ; \mathrm{p}=0.043$; Cohen's $\mathrm{d}=0.06$ ) and in the

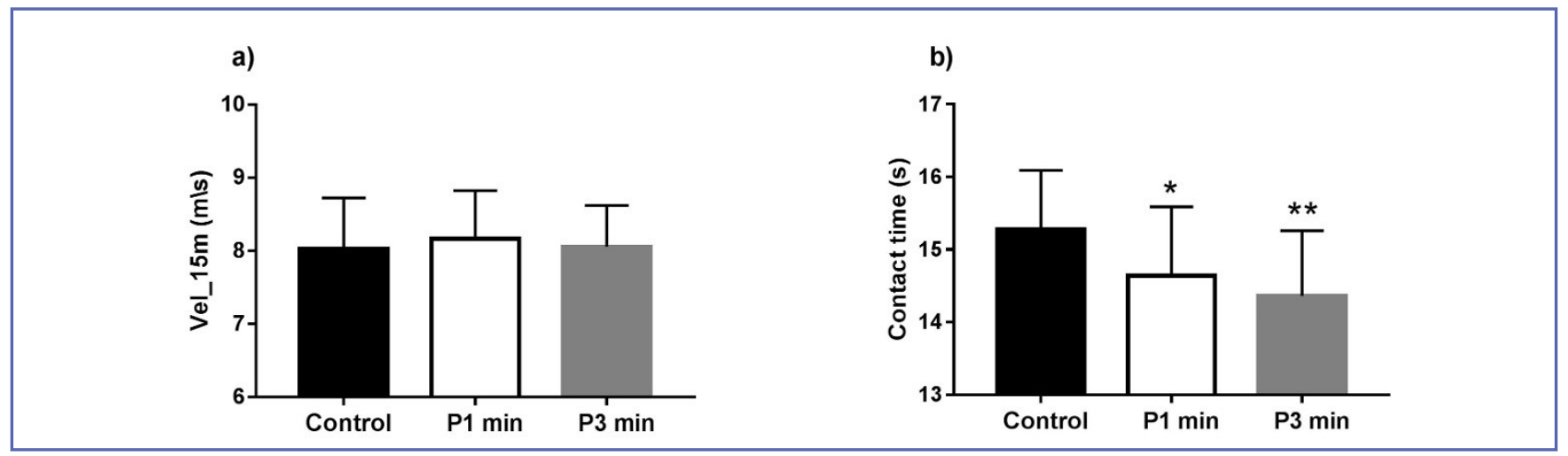

Figure 2. Approach velocity and contact time.

P1: rest of 1 min after plyometric exercise; P3: rest of 3 min after plyometric exercise. a) Vel_15m: approach velocity at 15 meters; b) Control vs P1 * (p $=0.05)$ and $\mathrm{P} 3(* * \mathrm{p}=0.009)$. 
P3min group $(173.44 \pm 12.70 \mathrm{~cm}$ vs $182.30 \pm 10.68 \mathrm{~cm}$; $\mathrm{p}=$ 0.005 ; Cohen's $d=0.07$ ) (figure $4 \mathrm{~b}$ ). The differences among approach velocity (figure $\mathbf{2}$ a), CMJ (F figure 3 a), SJ (figure $3 \mathbf{b}$ ), and jump distance (figure 4 a) did not differ statistically.
The jump distance presented a positive correlation when compared to vel_15m ( $\mathrm{r}=0.955 ; \mathrm{p}<0.001)$; CMJ $(\mathrm{r}=0.367$; $\mathrm{p}=0.017)$; and height $(\mathrm{r}=541 ; \mathrm{p}<0.001)$. Figure 5 is the graphical representations of the respective correlations. a)

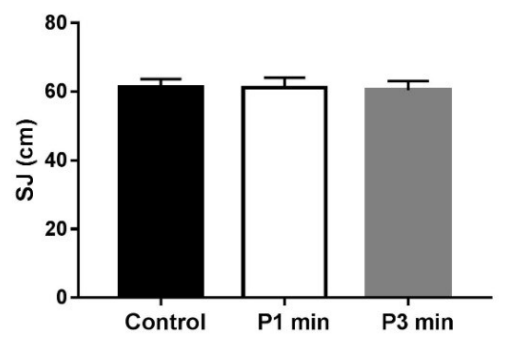

b)

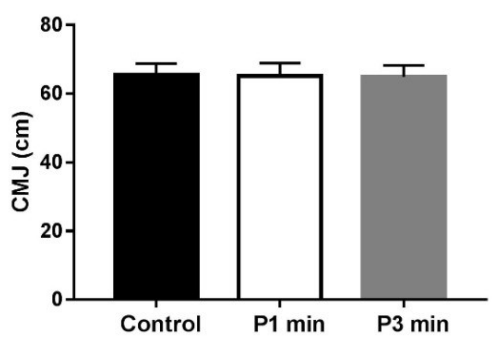

Figure 3. Counter movement jump and squat jump.

CMJ: counter movement jump; SJ: squat jump. P1: rest of 1 min after plyometric exercise; P3: rest of 3 min after plyometric exercise.

a)

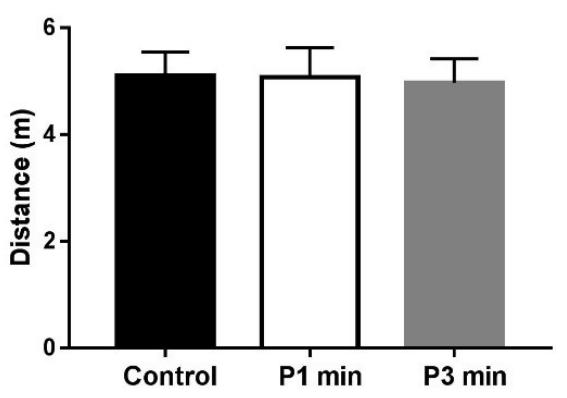

b)

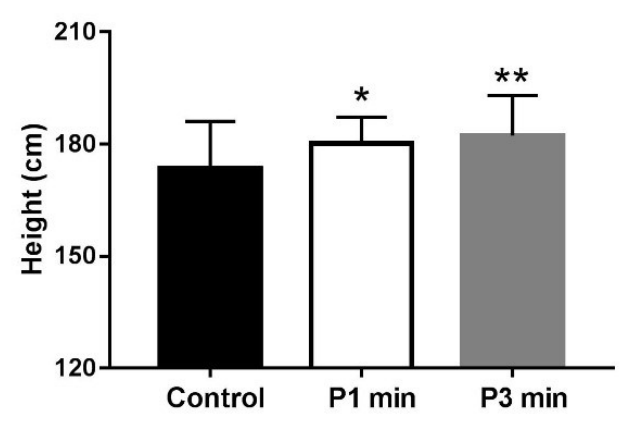

Figure 4. Jump distance and height.

P1: rest of 1 min after plyometric exercise; P3: rest of 3 min after plyometric exercise. b) Control vs P1 (*p $=0.043)$ and P3 (** p $=0.005)$.
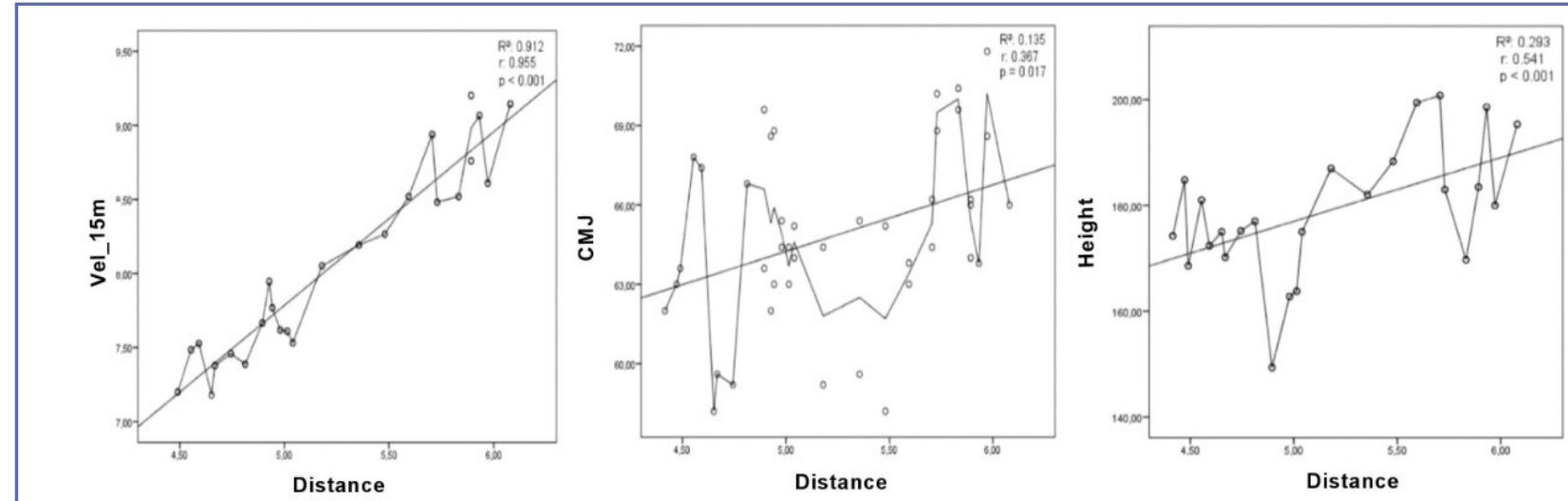

Figure 5. Correlation between long jump variables after plyometric exercise.

Vel_15m: approach velocity in 15 meters; CMJ: counter movement Jump; SJ: squat jump height. 


\section{DISCUSSION}

The aim of this study was to evaluate the effect of PE as a PAP strategy on the performance of long jumpers under three different interval conditions. The acute PE was potentially related to improved impulse contact time and jump height after 1 and $3 \mathrm{~min}$ of recovery, with no effect on approach run speed, CMJ, SJ, or jump distance.

Warm-up routines that include PE as a PAP strategy for short jump sprints did not improve running speed. Similar studies have linked imminent decreased sprint time to a sequence of high-intensity $(16,17)$. No reduction in running time has also been presented even when applying different PAP stimuli: free weight elevations (power clean - 90\%/ $\mathrm{RM}),(16)$ and isometric movements (17).

However, in our study, we identified a circumstance cooperating to maintain the observed velocity or even masking the isolated effect of PAP on the sprint. To define the number of steps required up to the take-off board, all volunteers made specific markings in the running corridor. This strategy, common during long jump competitions, aims to favor running control by avoiding jump burns, assuming to provide the same acceleration condition for jumpers.

On the contrary, apparently independent of velocity, the contact time on the thrust board was reduced by approximately $4 \%$ in the P1min group and 6\% in the P3min group when compared to the control group. Although modified at both intervals (P1min and $\mathrm{P} 3 \mathrm{~min})$, the effect size indicated higher recovering power (Cohen's $d=1.06$ ) in the P3min group, corroborating to recovery magnitude dependent on rest time $(1,7)$ as well as evidence identified increased velocity in vertical impulsion after P3min (1). Contradictorily moderate recovery intervals were previously identified as ineffective, even after a 4-min interval (7), and long passive intervals (9 min) were identified as effective to improve power (18).

Interestingly, even without performance gains in horizontal running speed, there was a reduction in the contact time on the push board, supposedly favored by the specificity of plyometric movement with vertical jump, related to better conditions for the vertical force vector (19). A possible increase in vertical velocity during mechanical take-off movement optimizes thrust for accurate and agile reactivity (20).

In both conditions, there was also an increase in the long jump height in the P1min and P3min groups by approximately $4 \%$ and $5 \%$, respectively, when compared to the control group, presuming that gains in speed and vertical power (1) increase in the activation and recruitment of motor units, especially fast fibers (10), and higher production of synaptic neurotransmitters (21). Although this result is found to be favorable in horizontal jumps, increasing the vertical height alone does not improve distance perfor- mance. It is well known that yield gains in this embodiment are influenced by a sum of fundamental technical factors such as angle and thrust velocity (22). In addition, large performance gains only in vertical components are likely to exert negative effects on long jump, better indicated for specific vertical jump evidence (e.g., high jump).

Regardless of a moderate correlation between horizontal jump distance and vertical factors (figure $5 \mathbf{c}$ ), no changes were observed in CMJ and SJ. Nevertheless, this result suggests absence of muscle fatigue (23), supporting other reports of low fatigue resulting from plyometric stimuli when compared to resistance exercises (24). On the contrary, increase in CMJ and SJ height associated with the use of active warming is well documented. Stimulating blood flow and an improvement in strength-to-speed ratio (25), receptors, and nerve impulses are also related to vasodilation and increases in muscle temperature, resulting in faster and stronger muscle contraction (26).

\section{Limitations}

This study has some limitations, there was difficulty in recruiting volunteers with competitive experience analyzing a small sample size, in addition to the fact that not evaluated the long jump output velocity and vertical impulse velocity. This information may be relevant to performance in the long jump. Furthermore, others factors need to be considered when evaluating the effects of PAP, including load used, volume, as well as individual variability including training and chronological age, sex, and strength levels. further studies are necessary.

\section{Practical applications}

Improvements in contact time and in the height of the long jump with intervals varying between 1 and 3 min reflect potential improvements in the vertical impulse mechanism. Although in the long jump, the main objective is to face the horizontal distance reached, vertical thrust gains are secondary factors that, if well executed, optimize the development of important techniques used for pedaling and the body arc performed in the air. These techniques have a high degree of difficulty and are poorly developed in young athletes. This significantly enhances the relationship between PE and vertical factors, which are significantly correlated with horizontal factors, which reinforces this outcome.

Further investigations of PAP with exercises aimed exclusively at the horizontal axis are recommended, but the development of complementary strategies is also essential, provided the engineering of biomechanical mechanisms of long jump. 


\section{CONCLUSIONS}

From the current results, PE can be an effective strategy to reduce the contact time on the jump board and increase height of the jump in young competing in long jump. We evidence the importance minimum period of 1 minute rest

\section{REFERENCES}

1. Bogdanis GC, Tsoukos A, Veligekas P. Improvement of Long Jump Performance During Competition Using a Plyometric Exercise. Int J Sports Physiol Perform 2017;12(2):235-40.

2. Wilson JM, Duncan NM, Marin PJ, Brown LE, Loenneke JP, Wilson SM, Jo E, Lowery RP, Ugrinowitsch C. Meta-analysis of postactivation potentiation and power: Effects of conditioning activity, volume, gender, rest periods, and training status. J Strength Cond Res 2013;27: 854-9.

3. Kümmel J, kramer A, Cronin NJ, Gruber M. Postactivation potentiation can counteract declines in force and power that occur after stretching. Scand J Med Sci Sports 2017;27(12):1750-60.

4. Hodgson M, Docherty D, Robbins D. Post-activation potentiation: underlying physiology and implications for motor performance. Sports Med 2005;35(7):585-95.

5. Tillin NA, Bishop D. Factors modulating post-activation potentiation and its effect on performance of subsequent explosive activities. Sports Med 2009;39(2):147-66.

6. Crewther BT, Kilduff LP, Cook CJ, Middleton MK, Bunce PJ, Yang GZ. The acute potentiating effects of back squats on athlete performance. J Strength Cond Res 2011;25(12):3319-25.

7. Turner AP, Bellhouse S, Kilduff LP, Russell M. Post activation potentiation of sprint acceleration performance using plyometric exercise. J Strength Cond Res 2015;29(2):343-50.

8. Rixon KP, Lamont HS, Bemben MG. Influence of type of muscle contraction, gender, and lifting experience on postactivation potentiation performance. J Strength Cond Res 2007;21(2):500-5.

9. Robbins DW. Post activation potentiation and its practical applicability: a brief review. J Strength Cond Res 2005;19 (2):453-8.

10. Gullich A, Schmidtbleicher D. MVC-induced short-term potentiation of explosive force. New Studies in Athletics 1996;11(4):67-81.

11. Seitz LB, Haff GG. Factors modulating post-activation potentiation of jump, sprint, throw, and upper-body ballistic performances: a systematic review with meta-analysis. Sports Med 2016;46(2):231-40.

12. Linder EE, Prins JH, Murata NM, Derenne C, Morgan CF, Solomon JR. Effects of preload 4 repetition maximum on $100-\mathrm{m}$ sprint times in collegiate women. J Strength Cond Res 2010;24(5):1184-90.

13. Padulo J, Oliva F, Frizziero A, Maffulli N. Muscles, Ligaments and Tendons Journal - Basic principles and recommendations between the conditioning activity and the target activity to improve performance.

\section{CONFLICT OF INTERESTS}

The authors declare that they have no conflict of interests.

in clinical and field science research: 2018 update. Muscles Ligaments Tendons J 2018;8(3):305-7.

14. Bosco C, Luhtanen P, Komi PV. A simple method for measurement of mechanical power in jumping. Eur J Appl Physiol Occup Physiol 1983;50:273-82.

15. Puig-Diví A, Escalona-Marfil C, Padullés-Riu JM, Busquets A, Padullés-Chando X, Marcos-Ruiz D. Validity and reliability of the Kinovea program in obtaining angles and distances using coordinates in 4 perspectives. PLoS One 2019;14(6):e0216448.

16. Guggenheimer JD, Dickin DC, Reyes GF, Dolny DG. The effects of specific preconditioning activities on acute sprint performance. J Strength Cond Res 2009;23(4):1135-9.

17. Till KA, Cooke C. The effects of postactivation potentiation on sprint and jump performance of male academy soccer players. J Strength Cond Res 2009;23(7):1960-7.

18. Boullosa DA, Abreu L, Beltrame LG, Behm DG. The acute effect of different half squat set configurations on jump potentiation. J Strength Cond Res 2013; 27(8):2059-66.

19. Loturco I, Contreras B, Kobal R, et al. Vertically and horizontally directed muscle power exercises : Relationships with top-level sprint performance. PLoS One 2018;13(7):e0201475.

20. Baker D, Nance S, Moore M. The load that maximizes the average mechanical power output during jump squats in power-trained athletes. J Strength Cond Res 2001;15(1):92-7.

21. Lesinski M, Muehlbauer T, Büsch D, Granacher U. Acute effects of postactivation potentiation on strength and speed performance in athletes. Sportverletz Sportschaden 2013;27(3):147-55.

22. Hay JG. Biomecânica das técnicas desportivas. Interamericana 1981.

23. de Souza RF, de Matos DG, Ferreira ARP, et al. The effect of ibuprofen on muscle, hematological and renal function, hydric balance, pain, and performance during intense long-distance running. J Strength Cond Res 2020;34(7): 2076-83.

24. Seitz LB, de Villarreal ES, Haff GG. The temporal profile of postactivation potentiation is related to strength level. J Strength Cond Res 2014;28(3):706-15.

25. Behm DG, Button DC, Butt JC. Factors affecting force loss with prolonged stretching. Can J Appl Physiol 2001;26(3):261-72.

26. Faigenbaum AD, Bellucci M, Bernieri A, Bakker B, Hoorens K. Acute effects of diferent warm up protocols on fitness performance in children. J Strength Cond Res 2005;19(2):376-81. 